\title{
Papillary, Follicular, Hurthle Cell, Poorly Differentiated, and Anaplastic Thyroid Carcinoma pNOa TNM Finding v8
}

National Cancer Institute

\section{Source}

National Cancer Institute. Papillary, Follicular, Hurthle Cell, Poorly Differentiated, and Anaplastic Thyroid Carcinoma pN0a TNM Finding v8. NCI Thesaurus. Code C140928.

One or more cytologically or histologically confirmed benign lymph nodes. (from AJCC 8th Ed.) 